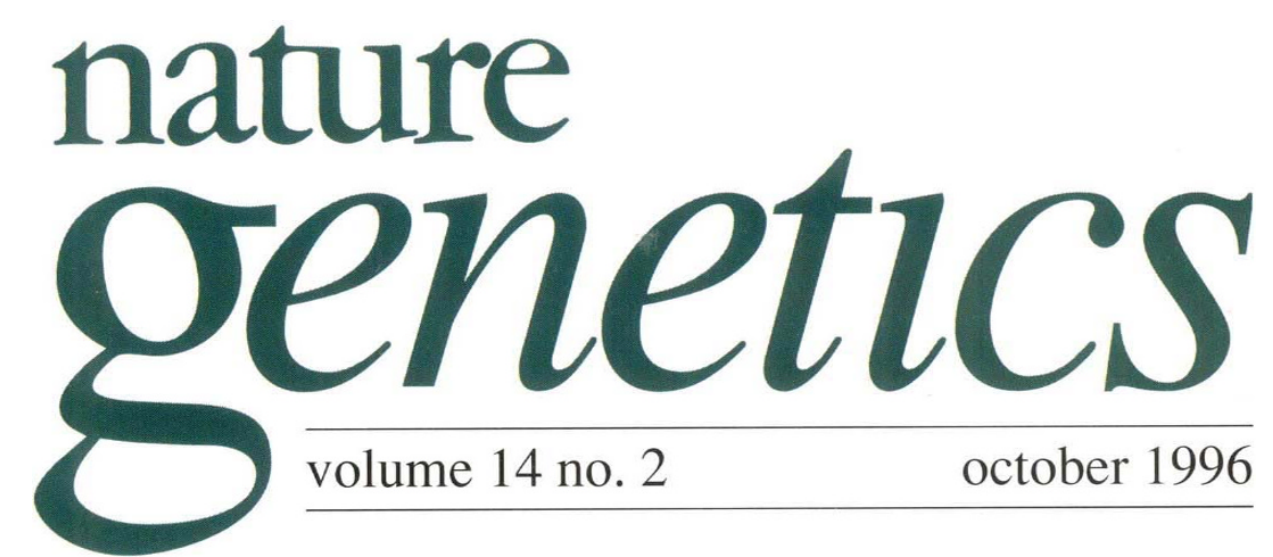

\title{
It takes a family
}

In 1972, two physicians at the University of Indiana, Robert McElroy and the late Philip Christiansen, published a paper in the American Journal of Medical Genetics on a large pedigree known as the 'S. family,' residing in the neighbouring state of Kentucky, that was affected with a rare autosomal dominant form of a disease called pancreatitis ${ }^{1}$. Affected individuals usually begin to show symptoms during childhood, suffering severe and untreatable (although not usually life-threatening) bouts of epigastric pain. The sporadic form, which is diagnosed more than 40,000 times each year in the United States, is usually attributable to diets rich in fatty foods or to alcohol, as well as to stress. Hereditary pancreatitis had first been reported in the literature 20 years earlier, in 1952, but although the 'S. family' was one of the largest pedigrees with the disorder on record, the report by McElroy and Christiansen was otherwise fairly unremarkable. The low prevalence and inability to treat the disease did little to generate interest among fellow researchers, and an attempt to map the gene in the late 1970s failed.

But for the Slone family, otherwise known as the 'S. family', the disease was anything but rare. Indeed, in large areas of Kentucky, their mysterious ailment was known simply as 'Slone's disease,' reflecting the spread of the branches of the family tree. In 1989, Kevin Slone, then a teenager, became so sick that he was admitted to hospital suffering from blood clots in his pancreas and kidney failure. He was officially diagnosed with hereditary pancreatitis, one of just a few hundred such diagnoses in the United States each year. The attacks were so severe that he had to be fed intravenously, and was not even allowed to suck ice chips. As Slone recently told the Wall Street Journal, "You don't realize how many food commercials are on TV until you can't eat." Kevin's father, Bobby, began to compile a family tree, hoping to chart the passage of the errant gene through his family. Likening himself to "a basketball player who throws the ball inbounds," Slone contacted relatives and friends, slowly piecing together information about his extended family and marking those who had suffered from the distinctive illness. The result was a pedigree of some 700 individuals spanning nine generations ${ }^{2}$.

While Slone was researching his personal genealogy, researchers at the University of Pittsburgh, led by David Whitcomb and Garth Ehrlich, decided to attempt to map and clone the gene for hereditary pancreatitis by collecting suitable family material. Whitcomb was hoping that the hereditary disorder would provide a good model for the more common (alcoholic) form of pancreatitis, and realised the project was feasible after Ehrlich localized the gene for Crouzon syndrome in 1994. 


\section{IMAGE \\ UNAVAILABLE FOR COPYRIGHT REASONS}

Pain in the pancreas. Two computer tomography (CT) scans from a patient with hereditary pancreatitis, demonstrating both acute and chronic features of the disease. a, Acute pancreatitis, showing extensive spreading of inflammation and fluid around the pancreas and kidney. $b$, Chronic pancreatitis, revealing pancreatic parenchyma with diffuse calcifications (solid arrow) and a dilated pancreatic duct (open arrow).

1. McElroy, R. \& Christiansen, P.A. Am. J. Med. 52, 228-241 (1972)

2. Bounds, W. Wall Street Journal 15 August, B1, B6 (1996).

3. Whitcomb, D.C. et al. Gastroenterology 110 , 1975-1980 (1996).

4. Le Bodic, L. et al. Hum. Mol. Genet. 5, 549554 (1996).

5. Rowen, L., Koop, B.F. \& Hood, L. Science 272 1755-1762 (1996).

6. Whitcomb, D. et al. Nature Genet. 14, 141-145 (1996).
Whitcomb contacted one of his former colleagues, a gastroenterologist named Lawrence Gates who had just set up a pancreatitis clinic at the University of Kentucky, and asked him to keep an eye out for suitable patients. Not long afterwards, Bobby Slone entered the clinic clutching a computerized print-out of his family tree. His son had just suffered another relapse, and had been admitted to hospital suffering from chronic pancreatitis (more than three quarters of his pancreas was scar tissue). The timing was especially fortunate, as Richard McElroy, the physician who had first worked with members of the Slone family, had retired and just thrown away his records, thinking that after two decades, no-one would have any need for them. The search for the $\mathrm{S}$. family was over; the hunt for the gene was just beginning.

Eighteen months ago, Bobby Slone convened a family reunion at a park on the Kentucky-Virginia border, and while 90 relatives swapped stories, doctors took blood samples. Progress was swift: by February this year, the Pittsburgh team had successfully mapped the gene for hereditary pancreatitis ${ }^{3}$ to the long arm of chromosome 7. A French group independently reached the same conclusion ${ }^{4}$. As luck would have it, the location not only coincided with the known position of a pair of trypsinogen genes, but was also in the vicinity of the $\beta$ T-cell receptor locus, the subject of a major sequencing effort by Lee Rowen and colleagues. Although their results ${ }^{5}$ were not yet published, much of the raw data had been deposited in GenBank, allowing the Pittsburgh team to exclude a number of trypsinogen pseudogenes in their search. Less than three months after the gene had been mapped, the gene had been found (see page 141) ${ }^{5}$.

Cationic trypsinogen is the precursor of trypsin, one of the digestive enzymes secreted by the pancreas. The zymogen is activated in the intestine, setting in motion a feedback loop in which trypsin catalyses its own conversion from the inactive precursor. Normally, a delicate balance of activation and enzymatic inhibition is maintained, ensuring that activated trypsin does not damage its host tissue. But when Whitcomb et al. ${ }^{6}$ examined the trypsinogen gene from affected members of the Slone family and four other pedigrees, they discovered an arginine-to-histidine missense mutation that segregated perfectly in each case. Based on X-ray crystallography data and good evidence that Arg 117 constitutes the main cleavage site during trypsin degradation, the authors believe that the Arg-to-His mutation disrupts this important cleavage site. As a result, trypsin autoactivation would probably proceed unchecked, and autodigestion of the pancreas thus ensues. Not all cases of hereditary pancreatitis are explained so neatly, however. Ehrlich's group has recently identified a different mutation in one of their families that seems to act somewhat differently.

One of the immediate benefits of the discovery is the opportunity to offer counselling to members of affected families such as the Slones. Family members are being contacted and offered the opportunity to undergo genetic testing, which many have indicated they would like to receive. With the basis for hereditary pancreatitis at least partially understood, the possible association of trypsinogen variants with the sporadic disease can be examined. Work is also in progress to produce valid mouse models of the hereditary disease, in the hope of developing some effective therapies where at present, there are none.

Since the first description of a family with hereditary pancreatitis in 1952, only about two families per year on average have been recorded, perhaps explaining in part why study of this rare disease was never a priority for the genetics community. Nevertheless, the identification of the gene offers yet another telling example of how rapidly research can move from linkage to locus. The authors believe their success owes a great deal to the Human Genome Project and the welcome existence of hundreds of kilobases of genomic sequence in their candidate region. It also serves as a testimonial to the tireless cooperation of long-suffering families such as the Slones. After decades of cooperation with the research community, it would be fitting if they can finally reap some benefit. 